\title{
Desenvolvimento de um submodelo bicompartimental para estimação da fração digestível da proteína bruta em bovinos a partir da composição química dos alimentos
}

\author{
Edenio Detmann ${ }^{1}$, Karla Alves Magalhães ${ }^{2}$, Sebastião de Campos Valadares Filho ${ }^{1}$, Mário \\ Fonseca Paulino ${ }^{1}$, Lara Toledo Henriques ${ }^{3}$
}

\footnotetext{
${ }^{1}$ Departamento de Zootecnia, Universidade Federal de Viçosa, Viçosa-MG, CEP: 36571-000. Bolsista do CNPq.

2 Programa de Pós-graduação em Zootecnia - UFV. Bolsista do CNPq.

${ }^{3}$ Bolsista PRODOC-CAPES, DZO-UFV.
}

RESUMO - Objetivou-se propor e validar um submodelo bicompartimental para estimação da fração protéica aparentemente digestível $\left(\mathrm{PB}_{\mathrm{ad}}\right)$ em alimentos ofertados a bovinos em condições tropicais. Os dois compartimentos teóricos utilizados como base para o submodelo foram proteína bruta de conteúdo celular (PBCC) e proteína bruta de parede celular (PBPC). O teor de proteína insolúvel em detergente neutro (PIDN) foi utilizado como aproximação analítica para PBPC. A avaliação das frações digestíveis verdadeiras da PBCC e da PBPC se baseou no conceito de entidade nutricional e na disponibilidade potencial a partir da proteína indegradável insolúvel em detergente neutro (PIIDN), respectivamente. A estrutura básica do submodelo foi: $\mathrm{PB}_{\mathrm{ad}}(\% \mathrm{MS})=0,98 \times(\mathrm{PB}-\mathrm{PIDN})+0,835 \times(\mathrm{PIDN}-\mathrm{PIIDN})-1,61$ e PB ${ }_{\mathrm{ad}}(\% \mathrm{MS})=$ $0,98 \times(\mathrm{PB}-\mathrm{PIDN})+0,67 \times($ PIDN - PIIDN $)-0,97$ para bovinos em crescimento e terminação e vacas em lactação, respectivamente. A validação do submodelo foi realizada a partir dos resultados obtidos em dois ensaios com bovinos em crescimento e terminação envolvendo oito alimentos. O submodelo apresentou estimativas similares às obtidas in vivo. As estimativas de $\mathrm{PB}_{\mathrm{ad}}$ foram também obtidas a partir de um submodelo unicompartimental previamente proposto. As estimativas produzidas pelo novo submodelo apresentaram maior exatidão e precisão em comparação às obtidas pelo submodelo unicompartimental.

Palavras-chave: digestibilidade aparente, nutrientes digestíveis totais, proteína de conteúdo celular, proteína de parede celular

\section{Development of a bicompartimental sub model to estimate digestible fraction of crude protein in cattle from chemical composition of feed}

\begin{abstract}
The objective was to propose and validate a bicompartimental sub model to estimate the apparently digestible crude protein fraction $(\mathrm{CPad})$ in feed offered to cattle in tropical conditions. The two theoretical compartments used as basis for the sub model were crude protein from cell content (CPCC) and crude protein from cell wall (CPCW). Feed content of neutral detergent insoluble protein (NDIP) was used as an analytical approach for CPCW. Evaluations of true digestible fractions of CPCC and CPCW were based on nutritional entity concept and on potential availability from undegradable neutral detergent insoluble protein (UNDIP), respectively. The basic structure of the sub model was: CPad $(\% \mathrm{DM})=0.98 \times(\mathrm{CP}-\mathrm{NDIP})+0.835 \times(\mathrm{NDIP}-\mathrm{UNDIP})-1.61$, and $\mathrm{CPad}(\% \mathrm{DM})=0.98 \times(\mathrm{CP}-\mathrm{NDIP})+0.67 \times(\mathrm{NDIP}$ - UNDIP) -0.97 for growing and finishing cattle and lactating dairy cows, respectively. The validation of sub model was made from results of two trials on growing and finishing cattle (eight feeds). The sub model showed estimates similar to those obtained in vivo. Estimates of CPad were also obtained from a previously proposed unicompartimental sub model. Estimates obtained by the bicompartimental sub model were more accurate and precise as compared to unicompartimental sub model.
\end{abstract}

Key Words: apparent digestibility, cell content protein, cell wall protein, total digestible nutrient

\section{Introdução}

A utilização da composição química dos alimentos como método de predição da digestibilidade em ruminantes tem sido sugerida por diversos autores (Conrad et al., 1984; Weiss et al., 1992; Van Soest, 1994). Nessa perspectiva, o
NRC (2001) propôs a adoção de método envolvendo a composição química dos alimentos para a estimação do teor de nutrientes digestíveis totais (NDT) dos alimentos, o qual constitui sistema somativo de equações em que, a cada grupo de compostos químicos (extrato etéreo - EE, fibra em detergente neutro - FDN, carboidratos não-fibrosos - CNF, 
e proteína bruta - PB), destina-se uma equação para obtenção de estimativas das frações verdadeiramente digestíveis, com posteriores correções relativas a perdas metabólicas e nível de consumo.

Contudo, embora seja um sistema teoricamente embasado (Conrad et al., 1984; Weiss et al., 1992), esse método tem apresentado eficiência de predição não satisfatória quando aplicado a alimentos obtidos em condições tropicais (Detmann et al., 2008).

A partir das características teóricas básicas de um sistema somativo, estabelece-se que as divergências das estimativas finais obtidas (neste caso, de NDT) constituem somatório simples das divergências observadas para cada equação (ou grupo de compostos) separadamente. Desta forma, possíveis correções ou alterações sobre qualquer sistema somativo devem ser investigadas quanto às estimativas de frações individuais.

Como alternativa ao sistema adotado pelo NRC (2001), Detmann et al. (2008) propuseram a utilização de novo sistema somativo para predição do teor de NDT em dietas para bovinos a partir de informações obtidas em condições tropicais, o qual se mostrou mais acurado e preciso em comparação ao sistema anteriormente descrito.

De forma particular, o submodelo destinado à predição do teor dietético de proteína bruta digestível adotado por Detmann et al. (2008) baseia-se na consideração da proteína bruta dos alimentos como entidade nutricional homogênea (Detmann et al., 2006a), segundo as pressuposições apresentadas por Lucas \& Smart (1959) e Lucas (1960).

Contudo, particularmente em condições tropicais, observam-se dietas com altos teores de compostos nitrogenados associados à parede celular vegetal, o que pode comprometer as estimativas obtidas pelo submodelo adotado por Detmann et al. (2008), em razão das diferenças na digestibilidade (Sniffen et al., 1992) e na contribuição metabólica fecal entre os compostos nitrogenados associados à parede celular e aqueles característicos do conteúdo celular.

Os componentes da FDN não podem ser considerados entidades nutricionais homogêneas (Van Soest, 1994), fato que pode comprometer a avaliação da PB associada à parede celular vegetal, segundo pressupostos de Lucas (1960), como adotado por Detmann et al. (2006a; 2008). Assim, a consideração da massa de PB no alimento como entidade homogênea poderia conduzir a distorções em estimativas de fração aparentemente digestível a partir da composição química dos alimentos produzidos em condições tropicais.

Objetivou-se neste estudo desenvolver e validar um submodelo para estimação da fração protéica dietética aparentemente digestível em bovinos alimentados em condi- ções tropicais, considerando a PB dos alimentos de forma bicompartimental (PB de conteúdo celular e PB associada à parede celular vegetal).

\section{Material e Métodos}

O novo submodelo foi desenvolvido tomando-se como base teórica para geração dos dois compartimentos - os quais foram pressupostos independentes - a diferença na utilização ruminal e intestinal dos compostos nitrogenados oriundos do conteúdo celular e da parede celular vegetal (Sniffen et al., 1992; Van Soest, 1994), segundo a estrutura básica:

$\mathrm{PB}_{\mathrm{ad}}=\mathrm{PBCC}_{\mathrm{ad}}+\mathrm{PBPC}_{\mathrm{d}} \quad$ (equação 1); em que: $\mathrm{PB}_{\mathrm{ad}}=\mathrm{PB}$ aparentemente digerida (\% da MS); $\mathrm{PBCC}_{\mathrm{ad}}=\mathrm{PB}$ do conteúdo celular aparentemente digerida $(\%$ da MS $) ;$ e $\mathrm{PBPC}_{\mathrm{d}}=\mathrm{PB}$ de parede celular digerida $(\%$ da MS).

Na equação 1, o termo "aparentemente" foi associado somente à PBCC, uma vez que não é observada contribuição metabólica fecal de componentes de parede celular.

Em virtude da dificuldade analítica para avaliação do teor de PBPC, adotou-se a proteína insolúvel em detergente neutro (PIDN) como aproximação química deste parâmetro, dada sua simplicidade analítica e o fato de compor as rotinas laboratoriais de avaliação de alimentos para ruminantes. Desta forma, por aproximação química, fez-se:

$\begin{array}{ll}\mathrm{PBCC} \cong \mathrm{PB}-\mathrm{PIDN} & \text { (equação } 2 \mathrm{a} \text { ); } \\ \mathrm{PBPC} \cong \mathrm{PIDN} & \text { (equação } 2 \mathrm{~b} \text { ); }\end{array}$
de modo que todos os termos foram expressos em \% da MS.

Para estimação da fração aparentemente digestível da PB de conteúdo celular, a qual representa o primeiro compartimento do submodelo descrito na equação 1, adotaram-se como base os pressupostos do teste de entidade nutricional (Lucas \& Smart, 1959) e do sistema fatorial (Blaxter \& Mitchell, 1948), segundo derivações de Detmann et al. (2006a):

$\frac{\mathrm{d}\left(\mathrm{PBCCc} \times \mathrm{Da}_{\mathrm{PBCC}}\right)}{\mathrm{dPBCCc}}=\frac{\mathrm{d}\left(\mathrm{PBCCc} \times \mathrm{Dv}_{\mathrm{PBCC}}\right)}{\mathrm{dPBCCc}}-\frac{\mathrm{dPBm}}{\mathrm{dPBCCc}}$ (equação 3a);

$\mathrm{Da}_{\mathrm{PBCC}}=\mathrm{Dv}_{\mathrm{PBCC}}-\frac{\mathrm{dPBm}}{\mathrm{dPBCCc}} \quad$ (equação $\left.3 \mathrm{~b}\right) ;$

em que: $\mathrm{PBCCc}=\mathrm{PB}$ de conteúdo celular consumida $(\mathrm{kg} / \mathrm{dia})$; $\mathrm{Da}_{\mathrm{PBCC}}=$ coeficiente de digestibilidade da PB de conteúdo celular $(\mathrm{kg} / \mathrm{kg}) ; \mathrm{Dv}_{\mathrm{PBCC}}=$ coeficiente de digestibilidade verdadeira da $\mathrm{PB}$ de conteúdo celular $(\mathrm{kg} / \mathrm{kg})$; e $\mathrm{PBm}=$ fração metabólica fecal da PB (kg/dia), a qual constitui diferencial em relação ao consumo de PB de conteúdo celular. 
Convertendo-se a equação ( $3 \mathrm{~b}$ ) para a base percentual, obteve-se:

$\mathrm{PBCC} \times \mathrm{Da}_{\mathrm{PBCC}}=\mathrm{PBCC} \times \mathrm{Dv}_{\mathrm{PBCC}}-\mathrm{CM} \quad$ (equação $\left.4 \mathrm{a}\right)$; $\mathrm{PBCC}_{\mathrm{ad}}=\mathrm{PBCC}_{\mathrm{vd}}-\mathrm{CM} \quad$ (equação $4 \mathrm{~b}$ ); em que: $\mathrm{CM}=$ contribuição metabólica fecal da $\mathrm{PB}(\%$ da MS); $\mathrm{PBCC}_{\mathrm{vd}}=\mathrm{PB}$ de conteúdo celular verdadeiramente digerida (\% da MS).

Sob o pressuposto da ausência de contribuição metabólica para componentes de parede celular, a avaliação da fração digestível da PB de parede celular, correspondente ao segundo compartimento da equação 1 , foi definida como: $\mathrm{PBPC}_{\mathrm{d}}=\mathrm{Dv}_{\mathrm{PBPCpd}} \times \mathrm{PBPC}_{\mathrm{pd}} \therefore \mathrm{PBPC}_{\mathrm{d}}=\mathrm{Dv}_{\mathrm{PBPC}} \times(\mathrm{PIDN}-\mathrm{PIIDN})$

(equação 5);

em que: $\mathrm{PBPC}_{\mathrm{pd}}=\mathrm{PB}$ de parede celular potencialmente digestível (\% da MS); $\mathrm{Dv}_{\mathrm{PBPCpd}}=$ coeficiente de digestibilidade verdadeira da PB de parede celular potencialmente digestível $(\mathrm{kg} / \mathrm{kg}) ;$ PIIDN = proteína indegradável insolúvel em detergente neutro (\% da MS).

Dessa forma, redefiniu-se o submodelo descrito na equação 1 como:

$$
\begin{array}{r}
\mathrm{PB}_{\mathrm{ad}}=\mathrm{PB}_{\mathrm{vd}}-\mathrm{CM} \\
\mathrm{PB}_{\mathrm{ad}}=\mathrm{Dv}_{\mathrm{PBCC}} \times(\mathrm{PB}-\mathrm{PIDN})+\mathrm{Dv}_{\mathrm{PCPC}} \times(\mathrm{PIDN}-\mathrm{PIIDN})-\mathrm{CM} \\
\text { (equação 6b); }
\end{array}
$$

em que: $\mathrm{PB}_{\mathrm{vd}}=\mathrm{PB}$ verdadeiramente digerida (\% da MS).

Adotou-se como estimativa do coeficiente de digestibilidade verdadeira para a PB de conteúdo celular o valor de $0,98 \mathrm{~kg} / \mathrm{kg}$, definido por Van Soest (1994) como média para a digestibilidade verdadeira de componentes de conteúdo celular.

As estimativas de contribuição metabólica da PB foram obtidas a partir de derivações de Detmann et al. (2006a). De outra forma, as estimativas do coeficiente de digestibilidade da PB de parede celular foram obtidas a partir de resultados de meta-análises estatísticas conduzidas por Detmann et al. (2007), pressupondo-se que a PB de parede celular potencialmente digestível apresenta o mesmo comportamento digestivo da fração potencialmente degradável da FDN.

Desta forma, redefiniu-se a equação 6 , para bovinos em crescimento e terminação e vacas em lactação, respectivamente, em condições de alimentação irrestrita (produção): $\mathrm{PB}_{\mathrm{ad}}=0,98 \times(\mathrm{PB}-\mathrm{PIDN})+0,835 \times(\mathrm{PIDN}-\mathrm{PIIDN})-1,61$

$$
\begin{array}{r}
\text { PB } \left.{ }_{\mathrm{ad}}=0,98 \times(\mathrm{PB}-\mathrm{PIDN})+0,67 \times(\mathrm{PIDN}-\mathrm{PIINN})-0,97 \text { aca }\right) ; \\
\text { (equação } 7 \mathrm{~b}) .
\end{array}
$$

Com base na relação entre teor dietético de NDT entre animais sob condições de alimentação restrita (mantença) e irrestrita (produção) apresentada por Costa et al. (2005) e nas derivações apresentadas por Detmann et al. (2006a; 2007), redefiniu-se a equação 7 para bovinos em crescimento e terminação e vacas em condições de mantença, respectivamente:

$$
\begin{array}{r}
\mathrm{PB}_{\mathrm{ad}}=0,98 \times(\mathrm{PB}-\mathrm{PIDN})+0,879 \times(\mathrm{PIDN}-\mathrm{PIIN})-1,17 \\
(\text { equação } 8 \mathrm{a}) ; \\
\mathrm{PB}_{\mathrm{ad}}=0,98 \times(\mathrm{PB}-\mathrm{PIDN})+0,705 \times(\mathrm{PIDN}-\mathrm{PIIDN})-0,43 \\
\text { (equação } 8 \mathrm{~b}) .
\end{array}
$$

O conceito analítico de PIIDN foi definido por Detmann et al. (2004) como aproximação ao valor paramétrico da proteína indegradável da parede celular e consiste da avaliação da PB residual do alimento após 240 horas de incubação ruminal in situ, seguida pelo tratamento da amostra com detergente neutro para remoção de debris microbianos. No entanto, essa aproximação analítica pode constituir empecilho em algumas situações, em virtude da não disponibilidade de animais fistulados. Desta forma, Clipes (2007) desenvolveu equação para obtenção alternativa dos valores de PIIDN a partir das concentrações de proteína insolúvel em detergente ácido (PIDA) utilizando informações de alimentos produzidos em condições tropicais $(n=540)$ : PIIDN $=\left(1,1557+0,0255 \times \text { PIDA }^{2,3388}\right)^{2} \quad$ (equação 9); em que: PIDA = proteína insolúvel em detergente ácido (\% da MS).

A avaliação do submodelo foi realizada com base em um banco de dados resultantes de dois ensaios conduzidos in vivo com bovinos em crescimento.

Os experimentos foram realizados nas dependências do Departamento de Zootecnia do Centro de Ciências Agrárias da Universidade Federal de Viçosa, em Viçosa, Minas Gerais, entre agosto e novembro de 2006.

No primeiro experimento, foram utilizadas 28 novilhas Nelore com peso vivo médio de $293 \mathrm{~kg}$, mantidas em regime de confinamento, alojadas em baias individuais cobertas, com piso de concreto revestido de borracha, de $3 \times 3 \mathrm{~m}$ de área, providas de comedouro e bebedouro individuais. $\mathrm{O}$ período experimental teve duração de 12 dias: sete para adaptação dos animais às dietas e cinco para as coletas totais de fezes.

Os tratamentos avaliados consistiram de volumosos fornecidos na forma exclusiva aos animais: cana-de-açúcar (Saccharum spp.); silagens de cana-de-açúcar, soja, capimmombaça (Pannicum maximum cv. Mombaça) e milho (Zea mays); feno de capim-tifton 85 (Cynodom spp.) e capim-elefante (Penissetum purpureum cv. Cameroon). Cada alimento foi ofertado a quatro animais.

A cana-de-açúcar e o capim-elefante foram colhidos diariamente nas proximidades do local do experimento. As silagens de soja e capim-mombaça foram produzidas na Central de Experimentação, Pesquisa e Extensão do Triângulo Mineiro (CEPET) da Universidade Federal de Viçosa, loca- 
lizada no município de Capinópolis, Minas Gerais. A soja utilizada foi o cultivar DM 339 (Pionner), colhida no estádio de desenvolvimento R6 (vagens com granação de 100\% e folhas verdes), a qual foi tratada com inoculante microbiano Sil All (Alltech do Brasil). Ambas as forragens foram ensiladas em tambores de plástico com $150 \mathrm{~L}$ de capacidade e transportadas até o local do experimento.

Para prevenir o efeito deletério do baixo teor de $\mathrm{PB}$ sobre o consumo e a digestibilidade, os volumosos com teores de PB inferiores a 7\% da MS (cana-de-açúcar, capimelefante e silagens de cana-de-açúcar, capim-mombaça e milho) foram corrigidos com uréia e sulfato de amônio (9:1) no momento do fornecimento para os animais, de modo que a dieta total contivesse aproximadamente $12 \%$ de PB.

As dietas foram fornecidas ad libitum duas vezes ao dia, às 6 h e às $15 \mathrm{~h} 30$, permitindo-se sobras de 5 a $10 \%$ do ofertado.

A coleta total de fezes foi realizada durante cinco dias consecutivos. Ao final de cada dia de coleta, as fezes foram homogeneizadas retirando-se alíquotas de $5 \%$ do total excretado. As amostras fecais foram pré-secas em estufa com ventilação forçada $\left(60^{\circ} \mathrm{C}\right)$, procedendo-se à confecção de amostra composta proporcional a cada excreção diária, por animal, com base no peso seco ao ar.

Durante o período de coletas, registrou-se diariamente a quantidade de alimento consumido e de sobras, coletando-se amostras de ambos, as quais foram secas sob ventilação forçada $\left(60^{\circ} \mathrm{C}\right)$ e trituradas em moinho de facas $(1 \mathrm{~mm})$.

No segundo ensaio, avaliou-se o capim-braquiária (Brachiaria decumbens Stapf) em pastejo utilizando-se quatro novilhas mestiças com grau de sangue predominantemente Nelore e peso vivo médio de $361 \mathrm{~kg}$.

A área experimental foi constituída de um piquete de aproximadamente 0,5 ha (disponibilidade média de $3,4 \mathrm{t}$ de MS/ha), com bebedouro e cocho para fornecimento de mistura mineral. O período experimental teve duração de 12 dias.

No primeiro dia do período de coleta, realizou-se a amostragem qualitativa do pasto por meio de simulação manual de pastejo (De Vries, 1995).

Para estimar a produção fecal, utilizou-se a LIPE ${ }^{\circledR}$ (lignina isolada, purificada e enriquecida do Eucalyptus grandis) como indicador externo, fornecida em cápsula, via esofágica, às 10 h, a partir do sétimo dia do período experimental, durante cinco dias consecutivos. A partir do $10^{\circ}$ dia, foram coletadas amostras fecais dos animais, em horários alternados, às $16 \mathrm{~h}$ no $10^{\circ} \mathrm{dia}$, às $12 \mathrm{~h}$ no $11^{\circ} \mathrm{e}$ às 8 h no $12^{\circ}$ dia.

As amostras de fezes foram processadas de forma similar ao descrito para o primeiro ensaio e enviadas à Escola de Veterinária da Universidade Federal de Minas Gerais, Belo Horizonte, Minas Gerais, para análise da LIPE ${ }^{\circledR}$ (método de absorbância em infravermelho), para estimação da produção de matéria seca fecal dos animais.

Para obtenção das estimativas de consumo voluntário, utilizou-se a fibra em detergente neutro indigestível (FDNi) como indicador interno, estimada por procedimento de incubação in situ por 240 horas (Casali et al., 2008). Utilizou-se como recipiente para as incubações sacos F57 (Ankom ${ }^{\circledR}$ ). As estimativas de consumo foram obtidas pela relação entre excreção fecal do indicador e sua concentração nas amostras de pasto.

As amostras de ambos os experimentos foram quantificadas quanto aos teores de matéria seca (MS), fibra em detergente ácido (FDA) e PB, de acordo com métodos descritos por Silva \& Queiroz (2002). Os teores de fibra em detergente neutro (FDN) foram obtidos segundo Mertens (2002), sem o uso de sulfito de sódio e utilizando-se amilase termoestável (Termamyl 120L, Novozymes). As estimativas de PIDN e PIDA foram obtidas segundo técnicas descritas por Licitra et al. (1996).

A partir das informações dietéticas médias (Tabela 1), os teores de PB aparentemente digestível foram preditos a partir da equação 7a, considerando os teores de PIIDN preditos pela equação 9. Ressalta-se que os animais utilizados neste estudo eram bovinos em crescimento e foram alimentados à vontade.

Comparativamente, os teores dietéticos médios de PB aparentemente digestível foram também preditos pelo submodelo unicompartimental adotado por Detmann et al. (2006a; 2008), representado, para a categoria animal utilizada neste estudo, por:

$\mathrm{PB}_{\mathrm{ad}}=0,7845 \times \mathrm{PB}-1,61 \quad$ (equação 10).

A avaliação da exatidão das estimativas dos teores dietéticos de PB aparentemente digestível obtidos por ambos os submodelos foi conduzida por meio do ajustamento de modelo de regressão linear simples de valores observados (variável dependente) sobre valores preditos (variável independente) e os testes estatísticos foram conduzidos sob as seguintes hipóteses (Mayer et al., 1994):

$$
\mathrm{H}_{0}: \beta_{0}=0 \text { e } \beta_{1}=1 \times \mathrm{H}_{\mathrm{a}}: \text { nãoH }_{0}
$$

No caso de não-rejeição da hipótese de nulidade, concluiu-se pela similaridade entre valores preditos e observados.

A avaliação comparativa da eficiência de predição entre submodelos foi realizada pela avaliação e partição do quadrado médio dos erros de predição (QMEP), segundo protocolos descritos por Kobayashi \& Salam (2000), conforme as equações:

$\mathrm{QMEP}=\mathrm{QV}+\mathrm{MaF}+\mathrm{MoF}=\frac{1}{\mathrm{n}} \sum_{\mathrm{i}=1}^{\mathrm{n}}\left(\mathrm{x}_{\mathrm{i}}-\mathrm{y}_{\mathrm{i}}\right)^{2} \quad$ (equação 11); 
Tabela 1 - Composição química dos alimentos

\begin{tabular}{lcccccc}
\hline & \multicolumn{6}{c}{ Item $^{1}$} \\
\cline { 2 - 7 } Alimento & $\mathrm{MS}^{2}$ & $\mathrm{~PB}^{3}$ & FDNcp $^{3}$ & PIDN $^{3}$ & PIDA $^{3}$ & PB $^{3,4}$ \\
\hline Cana-de-açúcar & 23,46 & 3,11 & 48,84 & 0,98 & 0,55 & 13,24 \\
Silagem de & 26,38 & 2,62 & 57,24 & 0,81 & 0,64 & 11,72 \\
cana-de-açúcar & & & & & & \\
Silagem de soja & 20,65 & 20,18 & 45,40 & 2,92 & 1,36 & - \\
Silagem de & 24,95 & 3,71 & 73,95 & 1,30 & 0,67 & 13,46 \\
mombaça & & & & & & \\
Silagem de milho & 24,10 & 6,09 & 56,07 & 1,34 & 0,75 & 12,23 \\
Feno de tifton & 90,65 & 13,87 & 74,49 & 1,43 & 1,27 & - \\
Capim-elefante & 23,96 & 6,25 & 70,12 & 1,67 & 0,67 & 12,20 \\
Capim-braquiária & 19,81 & 11,09 & 62,20 & 2,65 & 0,80 & - \\
\hline
\end{tabular}

${ }^{1} \mathrm{MS}=$ matéria seca; $\mathrm{PB}=$ proteína bruta; FDNcp = fibra em detergente neutro corrigida para cinzas e proteína; FDAcp = fibra em detergente ácido corrigida para cinzas e proteína; PIDN = proteína insolúvel em detergente neutro; PIDA = proteína insolúvel em detergente ácido; $2 \%$ da matéria natural; $3 \%$ da matéria seca; ${ }^{4} \%$ da matéria seca após correção com uréia e sulfato de amônio.

$\mathrm{QV}=(\overline{\mathrm{x}}-\overline{\mathrm{y}})^{2}$

$\mathrm{MaF}=\left(\mathrm{s}_{\mathrm{x}}-\mathrm{s}_{\mathrm{y}}\right)^{2}$

$\mathrm{MoF}=2 \times \mathrm{s}_{\mathrm{x}} \times \mathrm{s}_{\mathrm{y}} \times(1-\mathrm{r})$ em que: $\mathrm{x}=$ valores preditos; $\mathrm{y}=$ valores observados; QMEP = quadrado médio dos erros de predição; $\mathrm{QV}=$ quadrado do vício; $\mathrm{MaF}=$ componente relativo à magnitude de flutuação aleatória; $\mathrm{MoF}=$ componente relativo ao modelo de flutuação aleatória ponderado pelos desvios-padrão; $\mathrm{s}_{\mathrm{x}}$ e $\mathrm{s}_{\mathrm{y}}=$ desvios-padrão para valores preditos e observados, respectivamente; e $\mathrm{r}=$ correlação linear de Pearson entre valores preditos e observados.

Ressalta-se que, por se tratar de avaliação de erro de predição, empregou-se como divisor o total de observações (n) para todos os cálculos de variâncias (equações 11 a 14).

Todos os procedimentos estatísticos foram realizados utilizando-se o programa Statistical Analysis System (SAS, Institute, 1989).

\section{Resultados e Discussão}

As estimativas dos teores dietéticos de PB aparentemente digestível dos diferentes alimentos/dietas (Tabela 2) obtidas pelo novo submodelo bicompartimental foram similares às obtidas por observações in vivo $(\mathrm{P}>0,56)$, ao passo que as estimativas produzidas pelo submodelo unicompartimental proposto por Detmann et al. (2006a; 2008) divergiram dos valores observados $(\mathrm{P}<0,04)$ (Tabela 3$)$.

Este quadro pode ser reiterado pela inspeção do comportamento dos pontos em torno da reta de igualdade $(\mathrm{Y}=\mathrm{X})$ (Figura 1). Verificou-se maior agregação dos pares ordenados relativos ao novo submodelo em torno da reta de igualdade, em comparação aos pares ordenados oriundos do submodelo unicompartimental, os quais indicaram,
Tabela 2 - Teores de proteína bruta aparentemente digestível (\% da MS) observados e preditos pelo diferentes submodelos

\begin{tabular}{lccc}
\hline & \multicolumn{3}{c}{ Submodelo } \\
\cline { 2 - 4 } Alimento/Dieta & Observado $\begin{array}{c}\text { Detmann } \\
\text { et. (2006a) }\end{array}$ & Bicompartimental \\
\hline Cana-de-açúcar & 10,50 & 8,78 & 10,10 \\
Silagem de & 9,23 & 7,58 & 8,63 \\
cana-de-açúcar & & & 16,52 \\
Silagem de soja & 15,68 & 14,22 & 10,26 \\
Silagem de mombaça & 9,89 & 8,95 & 9,04 \\
Silagem de milho & 7,73 & 7,98 & 10,57 \\
Feno de Tifton & 10,47 & 9,27 & 8,97 \\
Capim-elefante & 9,41 & 7,96 & 7,73 \\
Capim-braquiária & 6,73 & 7,09 & 10,23 \\
Média & 9,96 & 8,98 & \\
\hline
\end{tabular}

sistematicamente, subestimação dos teores dietéticos de PB aparentemente digestível (Tabela 2; Figura 1).

A maior exatidão dos resultados obtidos pelo novo submodelo refletiu em menor erro médio de predição, e em menor vício, em comparação ao submodelo unicompartimental (Figura 2). Ressalta-se que somente o erro médio de predição associado ao modelo unicompartimental foi considerado significativo $(\mathrm{P}<0,02)$.

O teste de Lucas (Lucas \& Smart, 1959; Lucas 1960), base para a definição do submodelo de Detmann et al. (2006a; 2008) e para o compartimento associado à PB de conteúdo celular no novo submodelo, pressupõe, para que determinado componente do alimento possa ser considerado entidade nutricional, que este possua comportamento digestivo homogêneo, independentemente da fonte alimentar ou situação de alimentação (Van Soest, 1994; Detmann et al., 2006b) e apresente contribuição metabólica fecal não-nula (Lucas \& Smart, 1959).

Os pressupostos estabelecidos pelo teste de Lucas foram avaliados e validados por Detmann et al. (2006a) para o estabelecimento do modelo unicompartimental expresso pela equação 10. No entanto, segundo Van Soest (1994), os componentes do conteúdo celular vegetal, os quais, ao contrário dos componentes de parede celular, atendem aos quesitos de entidade nutricional estabelecidos por Lucas (1960), apresentam coeficiente de digestibilidade verdadeiro médio de 0,98 kg/kg. Detmann et al. (2006b), ao avaliarem os carboidratos não-fibrosos de dietas ofertadas a bovinos em condições tropicais, verificaram que esta estimativa é válida também nestas condições. Logo, esperarse-ia, caso a PB atendesse aos quesitos de entidade nutricional, como definido por Detmann et al. (2006a), coeficiente de digestibilidade verdadeiro próximo a $0,98, \mathrm{~kg} / \mathrm{kg}$, o que, contudo, não foi verificado (Equação 10). 
Tabela 3 - Estimativas dos parâmetros da regressão e níveis descritivos de probabilidade para o erro tipo I para as relações entre valores preditos (variável independente) e valores observados (variável dependente) para os níveis dietéticos de proteína bruta aparentemente digestível obtidos pelos submodelos avaliados

\begin{tabular}{lcc}
\hline & \multicolumn{2}{c}{ Submodelo } \\
\cline { 2 - 3 } Item & Detmann et al. (2006a) & Bicompartimental \\
\hline Intercepto & $-0,2439$ & 0,2917 \\
Coeficiente de & 1,1359 & 0,9448 \\
inclinação & & \\
Valor-P $^{1}$ & 0,0374 & 0,5608 \\
$\mathrm{r}^{2}$ & 0,9160 & 0,9287 \\
$\mathrm{~s}_{\mathrm{xy}}$ & 0,83 & 0,77 \\
\hline
\end{tabular}

${ }^{1} H_{0}: \beta_{0}=0$ e $\beta_{1}=1$.

Componentes fibrosos não atendem aos quesitos de entidade nutricional (Lucas \& Smart, 1959), pois não apresentam contribuição metabólica fecal (Van Soest, 1994) e, em razão da diversidade de interações físicas e químicas entre os componentes carboidratos e fenólicos, não permitem estabelecer padrão de digestibilidade homogêneo entre alimentos e situações de alimentação (Van Soest, 1994; Detmann et al., 2008).

Os alimentos produzidos em condições tropicais apresentam, em comparação aos obtidos em condições temperadas, alta proporção da PB associada a componentes fibrosos (Cabral et al., 2000), além de alta variabilidade na disponibilidade desta fração entre alimentos (Henriques et al., 2007). Desta forma, somente parte da PB presente no alimento poderia, estritamente, seguir os preceitos de entidade nutricional (PB de conteúdo celular).

Neste contexto, o coeficiente de digestibilidade verdadeira estabelecido por Detmann et al. (2006a) para a PB total do alimento (Equação 10) conduziria a subestimativas do teor de $\mathrm{PB}$ de conteúdo celular digestível, resultando, conseqüentemente, em subestimativas do teor total de PB aparentemente digestível, como observado neste trabalho (Tabela 2; Figuras 1 e 2).

Desta forma, a subdivisão da PB total contida no alimento conduziria a maior exatidão das estimativas dos teores dietéticos de PB aparentemente digestível (Tabela 3; Figura 2), em virtude, ao menos em parte, do melhor entendimento nutricional da PB de conteúdo celular no novo submodelo.

Além da maior exatidão, as estimativas produzidas pelo novo submodelo apresentaram maior precisão, fato observado principalmente em razão da menor estimativa do componente MaF (Figura 2). Esse comportamento implica melhor adequação do submodelo em predizer a dimensão dos desvios das observações a partir da média aritmética do conjunto de dados utilizado (Kobayashi \& Salam, 2000).
Grande parte da dificuldade para obtenção de estimativas precisas de frações digestíveis (e, conseqüentemente, de NDT) está relacionada à heterogeneidade no comportamento dos componentes associados à parede celular (Detmann et al., 2008), uma vez que meras aproximações químicas não são capazes de predizer precisamente as interações estabelecidas com os compostos fenólicos (Detmann et al., 2004; 2007).

A porção digestível da PB de parede celular é estimada no novo submodelo a partir de um conceito biológico de disponibilidade protéica potencial (PIIDN, equação 5) (Detmann et al., 2004), o qual, além de incorporar a consideração isolada da fração protéica de parede celular, absorve, naturalmente, a heterogeneidade entre alimentos e as

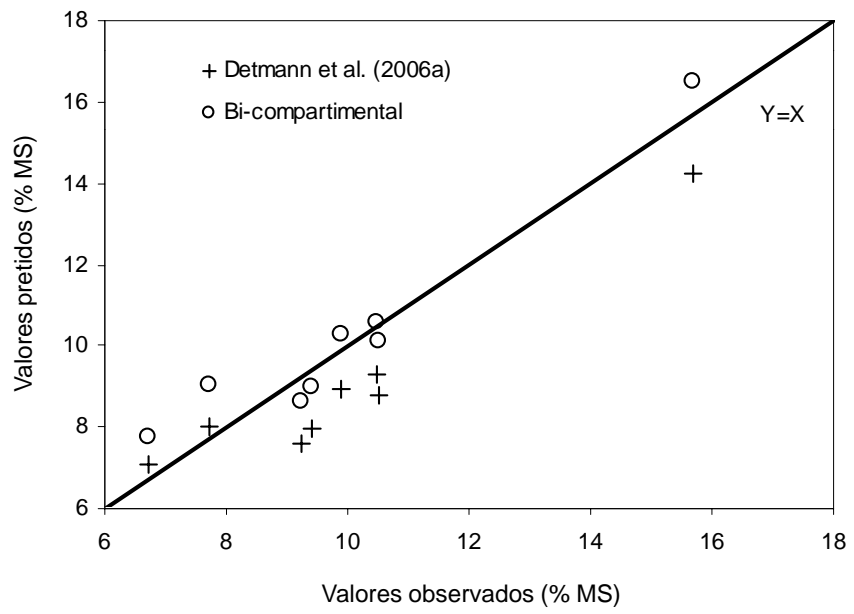

Figura 1 - Relação entre os valores preditos pelos submodelos e os observados para os teores de proteína bruta aparentemente digestível na dieta (\% da MS).

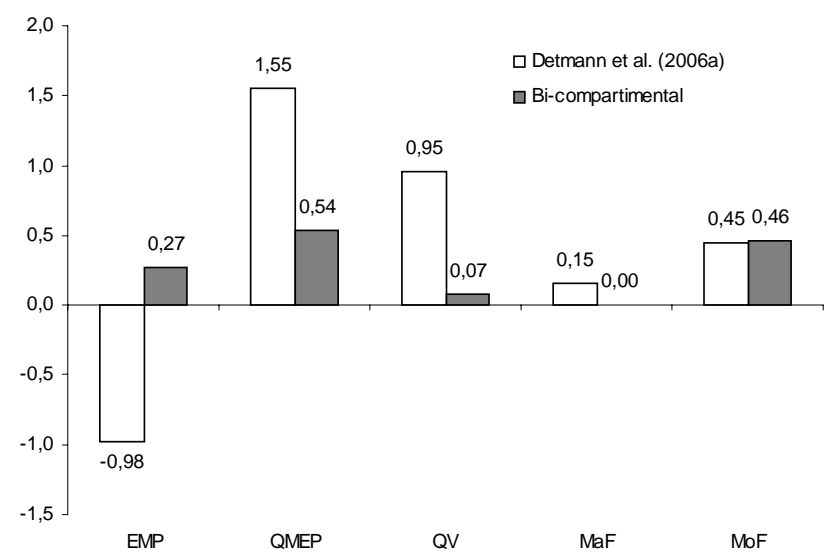

Figura 2 - Erro médio de predição (EMP) e quadrado médio do erro de predição (QMEP) e seus respectivos componentes para os teores dietéticos de proteína bruta aparentemente digestível (\% da MS) obtidos pelos submodelos avaliados (para maiores detalhes, ver equações 11 a 14). 
interações entre componentes protéicos, carboidratos e fenólicos.

Maiores ganhos em precisão e exatidão, contudo, poderiam ser observados pela obtenção de teores de PIIDN por meio de ensaios biológicos, como proposto por Detmann et al. (2004), uma vez que a Equação 9, embora agregue praticidade ao método, constitui apenas ferramenta de avaliação empírica a partir de aproximação química.

\section{Conclusões}

A utilização de submodelo bicompartimental, no qual são considedas as porções de proteína bruta de parede celular e conteúdo celular isoladamente, conduz a estimativas exatas da fração protéica aparentemente digestível dos alimentos produzidos em condições tropicais. O submodelo proposto neste estudo pode ampliar a acurácia do processo de predição energética via nutrientes digestíveis totais a partir da composição química dos alimentos.

\section{Literatura Citada}

BLAXTER, K.L.; MITCHELL, H.H. The factorization of the protein requirements of ruminants and of the protein values of feeds, with particular reference to the significance of metabolic fecal nitrogen. Journal of Animal Science, v.7, p.351-372, 1948.

CABRAL, L.S.; VALADARES FILHO, S.C.; MALAFAIA, P.A.M. et al. Frações protéicas de alimentos tropicais e suas taxas de digestão estimadas pela incubação com proteases ruminais. Revista Brasileira de Zootecnia, v.29, p.2316-2324, 2000 (supl. 2).

CASALI, A.O.; DETMANN, E.; VALADARES FILHO, S.C. et al. Influência do tempo de incubação e tamanho de partículas sobre os teores de compostos indigestíveis em alimentos e fezes bovinas obtidos por procedimento in situ. Revista Brasileira de Zootecnia, v.37, p.335-342, 2008.

CLIPES, R.C. Degradação ruminal de compostos fibrosos e nitrogenados em gramíneas tropicais. Campos dos Goytacazes: Universidade Estadual do Norte Fluminense, 2007. 74p. Tese (Doutorado em Produção Animal) - Universidade Estadual do Norte Fluminense, 2007

CONRAD, H.R.; WEISS, W.P.; ODWONGO, W.O. et al. Estimating net energy lactation from components of cell solubles and cell walls. Journal of Dairy Science, v.67, p.427-436, 1984.

COSTA, M.A.L.; VALADARES FILHO, S.C.; VALADARES, R.F.D. et al. Validação das equações do NRC (2001) para predição do valor energético de alimentos em condições brasileiras. Revista Brasileira de Zootecnia, v.34, p.280-287, 2005.

DETMANN, E.; CLIPES, R.C.; COELHO DA SILVA, J.F. et al. Avaliação da proteína insolúvel em detergente ácido como estimador da fração protéica indegradável no rúmen em forragens tropicais. In: REUNIÃO ANUAL DA SOCIEDADE BRASILEIRA DE ZOOTECNIA, 41., 2004, Campo Grande. Anais... Campo Grande: Sociedade Brasileira de Zootecnia, 2004 (CD-ROM).
DETMANN, E.; PINA, D.S.; VALADARES FILHO, S.C. et al. Estimação da fração digestível da proteína bruta em dietas para bovinos em condições brasileiras. Revista Brasileira de Zootecnia, v.35, p.2101-2109, 2006a.

DETMANN, E.; VALADARES FILHO, S.C.; HENRIQUES, L.T. et al. Estimação da digestibilidade dos carboidratos não-fibrosos em bovinos utilizando-se o conceito de entidade nutricional em condições brasileiras. Revista Brasileira de Zootecnia, v.35, p.1479-1486, 2006b.

DETMANN, E.; VALADARES FILHO, S.C.; HENRIQUES, L.T. et al. Reparametrização do modelo baseado na lei de superfície para predição da fração digestível da fibra em detergente neutro em condições brasileiras. Revista Brasileira de Zootecnia, v.36, p.155-164, 2007.

DETMANN, E.; VALADARES FILHO, S.C.; PINA, D.S. et al. Prediction of the energy value of cattle diets based on the chemical composition of the feeds under tropical conditions. Animal Feed Science and Technology, v.143, p.127-147, 2008.

De VRIES, M.F.W. Estimating forage intake and quality in grazing cattle: a reconsideration of the hand-plucking method. Journal of Range Management, v.48, p.370-375, 1995.

HENRIQUES, L.T.; DETMANN, E.; QUEIROZ, A.C. et al. Frações dos compostos nitrogenados associados à parede celular em forragens tropicais. Arquivo Brasileiro de Medicina Veterinária e Zootecnia, v.59, p.258-263, 2007.

KOBAYASHI, K.; SALAM, M.U. Comparing simulated and measured values using mean squared deviation and its components. Agronomy Journal, v.92, p.345-352, 2000.

LICITRA, G.; HERNANDEZ, T.M.; Van SOEST, P.J. Standardization of procedures for nitrogen fractionation of ruminant feeds. Animal Feed Science and Technology, v.57, p.347-358, 1996.

LUCAS, H.L. Relations between apparent digestibility and the composition of feed and feces. 1. A quantitative theory. Raleigh: North Caroline State College, 1960. 55p. (Technical Report).

LUCAS, H.L.; SMART, W.W.G. Chemical composition and the digestibility of forages. In: PASTURE AND CROP IMPROVEMENT CONFERENCE, 16., 1959, Mississipi. Proceedings... Mississipi: Mississipi State University, 1959. p.23-26.

MAYER, D.G.; STUART, M.A.; SWAIN, A.J. Regression of realworld data on model output: an appropriate overall test of validity. Agricultural Systems, v.45, p.93-104, 1994.

MERTENS, D.R. Gravimetric determination of amylase-treated neutral detergent fiber in feeds with refluxing in beakers or crucibles: collaborative study. Journal of AOAC International, v.85, p.1217-1240, 2002.

NATIONAL RESEARCH COUNCIL - NRC. Nutrient requirements of dairy cattle. 7.ed. Washington: Academic Press, 2001. 381p.

SAS Institute. SAS/STAT user's guide. 4.ed. Cary: SAS Institute, 1989. 1686p.

SILVA, D.J.; QUEIROZ, A.C. Análise de alimentos: métodos químicos e biológicos. 3.ed. Viçosa: Editora UFV, 2002. 235p.

SNIFFEN, C.J.; O'CONNOR, J.D.; Van SOEST, P.J. et al. A net carbohydrate and protein system for evaluating cattle diets: II. Carbohydrate and protein availability. Journal of Animal Science, v.70, p.3562-3577, 1992.

Van SOEST, P.J. Nutritional ecology of the ruminant. 2.ed. Ithaca: Cornell University Press, 1994. 476p.

WEISS, W.P.; CONRAD, H.R.; St.PIERRE, N.R. A theroticallybased model for predicting total digestible nutrient values of forage and concentrates. Animal Feed Science and Technology, v.39, p.95-110, 1992. 